\title{
Diversity of responses of soil saprobic fungi to recurring heat events
}

\author{
Aleksandra Szymczak ${ }^{1,2}$, Masahiro Ryo ${ }^{1,2}$ and Matthias C. Rillig ${ }^{1,2 *}$ \\ ${ }^{1}$ Freie Universität Berlin, Institute of Biology, D-14195 Berlin, Germany. \\ ${ }^{2}$ Berlin-Brandenburg Institute of Advanced Biodiversity Research, D-14195 Berlin, Germany.
}

*Author for correspondence: M. Rillig, matthias.rillig@fu-berlin.de

\begin{abstract}
As a consequence of ongoing climate change, the frequency of extreme heat events is expected to increase. Recurring heat pulses may disrupt functions supported by soil microorganisms, thus affecting the entire ecosystem. However, most perturbation experiments only test effects of single heat events, and therefore it remains largely unknown how soil microorganisms react to repeated pulse events. Here we present data from a lab experiment exposing 32 filamentous fungi, originally isolated from the same soil, to sequential heat perturbations. Soil saprobic fungi isolates were exposed to one or two heat pulses: mild $\left(35^{\circ} \mathrm{C} / 2 \mathrm{~h}\right)$, strong $\left(45^{\circ} \mathrm{C} / 1 \mathrm{~h}\right)$, or both in sequence $\left(35^{\circ} \mathrm{C} / 2 \mathrm{~h}+45^{\circ} \mathrm{C} / 1 \mathrm{~h}\right)$, and we assessed growth rate. Out of the 32 isolates 13 isolates showed an antagonistic response, 3 isolates a synergistic response and 16 isolates responded in an additive manner. These differences in species responses to the thermal environment may contribute to species coexistence, and such dissimilarities in thermal perturbation responses may be a key aspect influencing ecosystem services that soil saprobic fungi support.
\end{abstract}

Keywords: thermal stress, soil saprobic fungi, global change, climate extreme, multiple perturbation events, stress priming

\section{Introduction}

Climate warming is threatening ecosystems worldwide (IPCC 2018). Climate change does not only mean increased temperature averages but also increased frequency of extreme events, such as summer heatwaves (Bárcenas-Moreno et. al 2009; Hanson et. al 2006; Frank 
et al. 2015, IPCC 2018). Such extremes can profoundly influence individual physiological performance and fitness, phenotypic plasticity, demography and population dynamics, species interactions, and community structure (Vázquez et al. 2015 and references therein), probably even more so than an increase in mean conditions (Thompson et al. 2013).

Performances of soil microbes under an elevated average temperature have been widely investigated (Hortal et al. 2016), but the responses to heat pulse perturbations are understudied (Jentsch et al. 2007; Kreyling \& Beier 2013). Temperature pulse perturbations occurring within a short period of time can be especially damaging, because soil organisms may not be able to adjust their physiological response fast enough (Alley et al. 2003; Fisher \& Knutti 2015). Nevertheless, most temperature-related experimental designs have minimized temperature variability to solely focus on the effects of one average temperature (Thompson et al. 2013; Lloret et al. 2012). Understanding how heat pulse perturbations affect soil microbial performance is an important issue in soil ecology that could lead to a better understanding of aboveground and belowground community functioning.

In particular, the responses to multiple perturbations are far less understood but important, since multiple events may result in diverse response types because the effect size of a single event may depend on the antecedent event, known as ecological memory or carryover effect (Ryo et al. 2019). Considering the growing threat of recurrent heatwaves, it has been recently advocated that experiments aimed at investigating the impact of extreme weather events should consider that today's extremes will become the normal fluctuations in the future, and experimental designs should exceed the level of severity that we currently observe to provide an insight into an organism's responses to conditions harsher than those under which they evolved (Bahn et al. 2014; Kayler et al. 2015; Foster et al. 2016). Nevertheless, how soil saprobic fungi respond to recurrent temperature pulse perturbations is largely unknown.

The combination of multiple stressors (perturbations) can result in additive effects, detrimental effects (i.e. synergism) or cause a reduction in effects (i.e. antagonism) (Mittler 2006). Additive effects means that stressors do not interact and therefore the combined effect is simply the sum of each effect. Synergy results from a positive interaction, exceeding the sum of negative effects caused by each single stress event (Côté et al. 2016). Antagonism means that the combined effect is lower than the sum of each (negative) effect, 
such as observed in the form of stress priming ability (Rillig et al. 2015; Hilker et al. 2016). Priming ability means that a first exposure to a milder stress event induces protection mechanisms, consequently alleviating the effect of a subsequent stronger stress event (Rillig et al. 2015; Hilker et al. 2016; Andrade-Linares et al. 2016). While such different response types are theoretically possible, there is no study testing if such diverse responses to recurrent heat pulses are present in soil microbes co-occurring in the same environment. Additionally, studies on pulse temperature perturbations focus mostly on the community perspective, not providing information on species-level physiological responses (Norris et al. 2002; Allison \& Martiny 2008; Crowther \& Bradford 2013; Berard et al.2015; Zhou et al. 2017).

The purpose of the present study was to investigate the diversity of physiological responses of soil filamentous fungi to sequential high-temperature pulses exceeding current adverse extreme conditions. We investigated how recurrent temperature pulses affect the performance of individual fungi from a set of 32 soil filamentous fungi that had been isolated from the same soil. We exposed fungi to one or two high-temperature pulse perturbations differing in magnitude $\left(35^{\circ} \mathrm{C} / 2 \mathrm{~h}-\right.$ mild $(\mathbf{M}), 45^{\circ} \mathrm{C} / 1 \mathrm{~h}$ - severe $(\mathbf{S})$, and the sequence of these two perturbations $35^{\circ} / 2 \mathrm{~h}+45^{\circ} \mathrm{C} / 1 \mathrm{~h}$ (MS)) and measured growth responses (colony extension rates). We expected the following: (1) exposure of soil saprobic fungi to recurrent temperature pulses will lead to diverse, isolate-specific responses, and (2) the diversity of responses to recurrent pulse temperature disturbance is phylogenetically conserved.

\section{Materials and methods}

Isolates

Isolates of 32 soil fungi (Supplementary materials, Table S1) were originally cultured from the top $10 \mathrm{~cm}$ of soil in a semi-arid grassland in Mallnow Lebus, Brandenburg, Germany (Andrade-Linares et al. 2016). To obtain material for the experiment, $6.5 \mathrm{~mm}$ plugs were 
taken from the edge of fungal colonies and placed centrally on $9 \mathrm{~cm}$-diameter Petri dishes with PDA medium. Plates were then incubated at $22^{\circ} \mathrm{C}$ for 1 to 5 days, depending on individual colony extension rates, to obtain fresh and actively growing material for inoculation. Then, fungi were re-inoculated on fresh PDA plates and placed in incubators for the experiment.

\section{Heat treatment}

In the field where the fungi were collected, the topsoil (at approx. $10 \mathrm{~cm}$ depth) temperature recorded in the year $2018\left(52^{\circ} 52.778^{\prime} \mathrm{N}, 14^{\circ} 29.349^{\prime} \mathrm{E}\right.$ ) (Andrade-Linares et al. 2016) reached $32^{\circ} \mathrm{C}$ (Andrade-Linares et al. 2016, Dr. Max-Bernhard Ballhausen - personal information, data not shown). We used $35^{\circ} \mathrm{C} / 2 \mathrm{~h}$ as the mild perturbation (M) pulse temperature, since it is a temperature outside of the range of optimal growth conditions for half of the tested isolates, and it resulted in growth reduction in half of the tested fungi (Andrade-Linares et al. 2016). As the severe perturbation (S), we used $45^{\circ} \mathrm{C}$ applied for $1 \mathrm{~h}$ since the responses to this temperature were severe for most of the isolates in our set (Andrade-Linares et al. 2016).

The full factorial experiment consisted of the following treatments: control (C) $22^{\circ} \mathrm{C}$; mild perturbation (M) $\left(35^{\circ} \mathrm{C} / 2 \mathrm{~h}\right)$; severe perturbation $(\mathrm{S})\left(45^{\circ} \mathrm{C} / 1 \mathrm{~h}\right)$; sequence of the two perturbations (MS) $\left(35^{\circ} \mathrm{C} / 2 \mathrm{~h}+45^{\circ} \mathrm{C} / 1 \mathrm{~h}\right)$.

Temperature pulses were applied uniformly to all 32 soil saprobic fungi. Each treatment consists of three replicates, with incubators used as experimental units. First, samples were incubated for 2-6 days to allow a fungal colony to begin growing from the inoculated plug. Then fungi were exposed to the different pulse temperature perturbations.

\section{Measurements}




\section{Trait measurements}

The colony diameter of each isolate was measured for each Petri dish in two directions, at right angles to each other. Such measurements were taken four times - the first time before starting heat treatments to determine initial colony size, and then three more times after the treatment to define the response to heat exposure. The frequency of diameter measurements was isolate dependent and taken daily for fast-growing fungi or every 2-4 days for slow-growing individuals.

Thereby, in total 1,536 data points were acquired (i.e. 32 isolates $\times(2$ temperatures magnitudes $(M, S)+1$ temperature combination $(M S)+$ control $(C)) \times 3$ replicates $\times 4$ time points). The diameter was measured repeatedly to calculate colony extension rate ( $\mathrm{mm}$ day 1).

\section{Statistical analyses}

Colony extension rates after heat treatments were used as a response variable to applied temperature pulses. Treatment effects were tested with two-way ANOVA where factors were the applied temperature regimes: mild perturbation ( $M$, yes/no) and stronger perturbation (S, yes/no). Note that the no-no combination indicates control, while the yesyes combination indicates two perturbations. The significance level $\alpha$ was set to 0.05 with Benjamini-Hochberg correction, to control for experiment-wise type I error rate.

We used this analysis to classify responses of fungi. Specifically, our response classification is based on additive null model expectations, used to identify interactions (antagony, synergy, additivity) between multiple perturbations (Crain et al. 2008; Côté et al. 2016). The additive null model has been reported to fit responses such as growth (colony extension) of an 
organism and is consistent with the use of ANOVA for factorial experimental data (Piggott et al. 2015; Côté et al. 2016). Response types were assigned to three groups (see Table 1). The effect direction of the two single perturbation effects in this study could be double negative (both single perturbations reduce the growth rate of the fungal isolate), opposing (one single perturbation increases the growth rate and the other single perturbation decreases the growth rate of the fungal isolate) or double positive (both single perturbations increase the growth rate of the fungal isolate) (Fig. 1). Those effect directions are crucial to assign response to interaction types (Crain et al. 2008).

In addition, our study can be viewed in the context of stress priming, for which criteria were previously established (Andrade-Linares et al. 2016): (1) negative effect of strong perturbation (S); (2) significant interaction between mild and strong perturbations, and; (3) the interaction term has a positive sign (MS $>S$ ).

Table 1. Interaction types describing the outcome of multiple stressors (perturbations) following Crain et al. (2008); Côté et al. (2016). M (milder perturbation), S (stronger perturbation), MS (both perturbations applied).

Individual treatment response

Additive

Synergy

Non-additive

\begin{tabular}{|c|c|c|c|}
\hline & & Synergy & Antagony \\
\hline ondition & $\begin{array}{l}\text { No significant } \\
\text { interaction term } \\
\text { between milder } \\
\text { perturbation (M) } \\
\text { and stronger } \\
\text { perturbation (S) }\end{array}$ & $\begin{array}{l}\text { A significant interaction } \\
\text { term between milder } \\
\text { perturbation }(\mathrm{M}) \text { and } \\
\text { stronger perturbation (S) }\end{array}$ & $\begin{array}{l}\text { A significant interaction } \\
\text { term between milder } \\
\text { perturbation }(\mathrm{M}) \text { and } \\
\text { stronger perturbation }(\mathrm{S})\end{array}$ \\
\hline
\end{tabular}




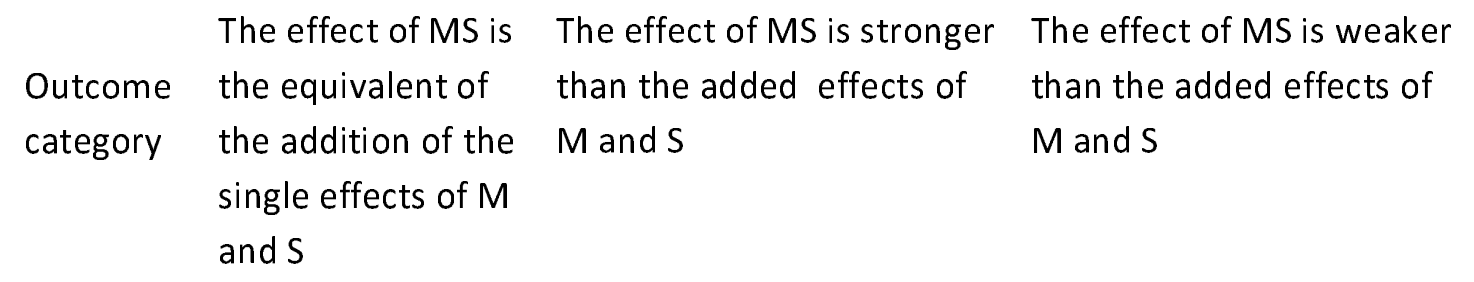

A

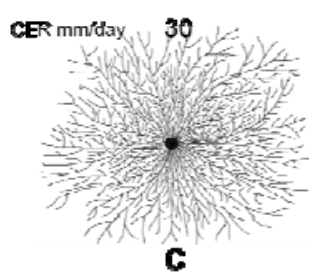

B

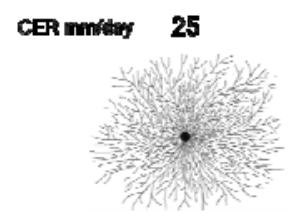

c

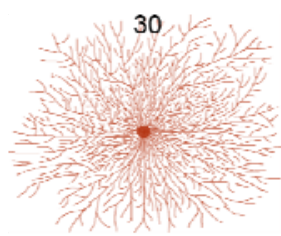

C

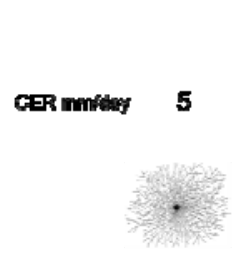

c i

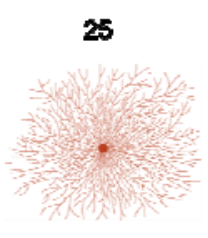

n

10

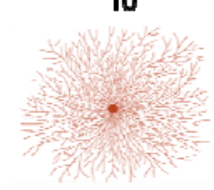

ต
15

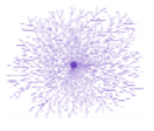

8

10

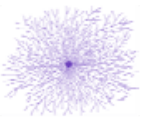

8

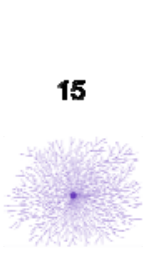

$\mathbf{s}$

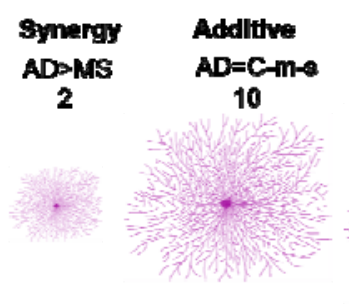

MS

MS

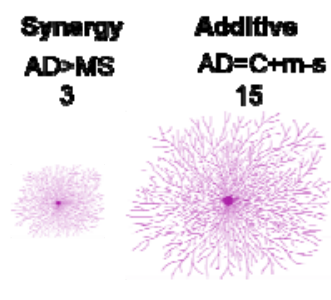

148

19

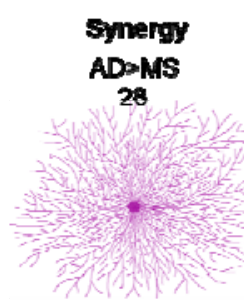

Additure

20

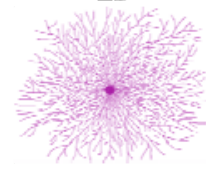

MS
Antagony

ADANS

22

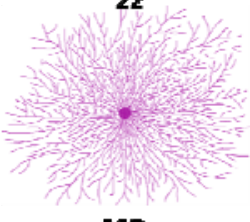

Ms

Figure 1. Redrawn from Crain et al. (2008) with adjusted conceptual approach for interpreting interaction types from factorial experiment response data. A full factorial study includes the following treatments: control (C), mild perturbation (M), strong perturbation (S) and both (MS). The three panels illustrate different combinations of individual responses: double negative (A), opposing (B), double positive (C). The numbers indicate example values of colony extension rate (proportional to the size of the mycelium). Interaction types (synergy, additive, antagony) depend on MS response in comparison with the sum (AD) of individual responses of single perturbations ( $m=C-M ; s=C-S$ ).

\section{Results}


Fungal isolates showed a range of responses to the applied sequences of temperature perturbation (Fig. 2, Fig. 3). There was a significant interaction term for the two perturbations $(\mathrm{M}: \mathrm{S})$ in 16 tested isolates, and these were further categorized as antagonistic (13 isolates) or synergistic ( 3 isolates; Table 2). Isolates that did not meet the criterion of a significant interaction term (M:S) were assigned to the category 'additive' (16 isolates) (Tables 1 and 2).

The observed antagonistic response is largely congruent (with small differences in categorization occurring, since two different statistical approaches are used - one isolate was classified differently) with what defines the priming ability of an organism (AndradeLinares et al. 2016). We found priming responses in 12 out of the 32 isolates - 3 Mucoromycotina, 2 Basidiomycota and 7 Ascomycota. That is, for these 12 isolates, growth was enhanced when fungi were exposed to a mild temperature pulse $(M)$ before the severe temperature (MS), compared to when they were only experiencing the severe pulse (S). For the remaining isolates exposure to experimental conditions of sequential perturbation (MS) did not lead to increased performance.

Table 2. Analysis of variance results of effects of mild ( $M$, yes/no), strong ( $S$, yes/no) and both heat stress events (MS). The full results table is available in Supplementary materials (Supplementary materials, Table S2).

\begin{tabular}{llllll}
\hline Isolate & Source & df & Sum Sq & F & $\begin{array}{c}\text { p-value } \\
\text { (enjamini- } \\
\text { Hochberg } \\
\text { corrected) }\end{array}$ \\
\hline \multirow{2}{*}{ RLCS09 } & Mild & 1 & 0.00 & 0.00 & 0.98 \\
& Strong & 1 & 0.00 & 0.01 & 0.97 \\
& Mild:Strong & 1 & 0.01 & 0.05 & 0.85 \\
& Residuals & 8 & 1.32 & & \\
\hline \multirow{2}{*}{ RLCS16 } & Mild & 1 & 0.20 & 0.64 & 0.57 \\
& Strong & 1 & 0.60 & 1.89 & 0.24 \\
& Mild:Strong & 1 & 0.02 & 0.06 & 0.85 \\
& Residuals & 8 & 2.54 & & \\
\hline
\end{tabular}


bioRxiv preprint doi: https://doi.org/10.1101/733923; this version posted August 14,2019 . The copyright holder for this preprint (which was not certified by peer review) is the author/funder, who has granted bioRxiv a license to display the preprint in perpetuity. It is made available under aCC-BY-NC-ND 4.0 International license.

\begin{tabular}{|c|c|c|c|c|c|}
\hline \multirow{4}{*}{ RLCS17 } & Mild & 1 & 0.19 & 1.94 & 0.38 \\
\hline & Strong & 1 & 1.84 & 19.16 & 0.01 \\
\hline & Mild:Strong & 1 & 1.45 & 15.09 & 0.01 \\
\hline & Residuals & 8 & 0.77 & & \\
\hline \multirow{4}{*}{ RLCS29 } & Mild & 1 & 0.00 & 0.01 & 0.96 \\
\hline & Strong & 1 & 1.25 & 61.86 & 0.00 \\
\hline & Mild:Strong & 1 & 0.51 & 25.24 & 0.00 \\
\hline & Residuals & 8 & 0.16 & & \\
\hline \multirow{4}{*}{ RLCS10 } & Mild & 1 & 1.36 & 10.76 & 0.03 \\
\hline & Strong & 1 & 1.16 & 9.22 & 0.02 \\
\hline & Mild:Strong & 1 & 0.82 & 6.49 & 0.06 \\
\hline & Residuals & 8 & 1.01 & & \\
\hline \multirow{4}{*}{ RLCS14 } & Mild & 1 & 1.40 & 26.14 & 0.00 \\
\hline & Strong & 1 & 0.15 & 2.72 & 0.18 \\
\hline & Mild:Strong & 1 & 0.79 & 14.74 & 0.01 \\
\hline & Residuals & 8 & 0.43 & & \\
\hline \multirow{4}{*}{ RLCS12 } & Mild & 1 & 8.66 & 63.93 & 0.00 \\
\hline & Strong & 1 & 6.84 & 50.45 & 0.00 \\
\hline & Mild:Strong & 1 & 5.02 & 37.04 & 0.00 \\
\hline & Residuals & 8 & 1.08 & & \\
\hline \multirow{4}{*}{ RLCS22 } & Mild & 1 & 0.01 & 0.23 & 0.73 \\
\hline & Strong & 1 & 0.23 & 6.91 & 0.04 \\
\hline & Mild:Strong & 1 & 0.07 & 2.05 & 0.24 \\
\hline & Residuals & 8 & 0.27 & & \\
\hline \multirow{4}{*}{ RLCS21 } & Mild & 1 & 0.26 & 1.64 & 0.40 \\
\hline & Strong & 1 & 7.05 & 44.20 & 0.00 \\
\hline & Mild:Strong & 1 & 0.47 & 2.93 & 0.18 \\
\hline & Residuals & 8 & 1.28 & & \\
\hline \multirow{4}{*}{ RLCS31 } & Mild & 1 & 0.00 & 0.40 & 0.65 \\
\hline & Strong & 1 & 0.84 & 119.36 & 0.00 \\
\hline & Mild:Strong & 1 & 0.03 & 3.95 & 0.12 \\
\hline & Residuals & 8 & 0.06 & & \\
\hline \multirow{4}{*}{ RLCS30 } & Mild & 1 & 0.02 & 1.42 & 0.43 \\
\hline & Strong & 1 & 1.72 & 102.66 & 0.00 \\
\hline & Mild:Strong & 1 & 0.01 & 0.59 & 0.55 \\
\hline & Residuals & 8 & 0.13 & & \\
\hline \multirow{4}{*}{ RLCS26 } & Mild & 1 & 0.03 & 15.26 & 0.01 \\
\hline & Strong & 1 & 6.04 & 2933.90 & 0.00 \\
\hline & Mild:Strong & 1 & 0.03 & 15.26 & 0.01 \\
\hline & Residuals & 8 & 0.02 & & \\
\hline \multirow{4}{*}{ RLCS28 } & Mild & 1 & 0.01 & 1.04 & 0.51 \\
\hline & Strong & 1 & 0.82 & 123.11 & 0.00 \\
\hline & Mild:Strong & 1 & 0.47 & 69.89 & 0.00 \\
\hline & Residuals & 8 & 0.05 & & \\
\hline \multirow{4}{*}{ RLCS07 } & Mild & 1 & 3.20 & 10.42 & 0.03 \\
\hline & Strong & 1 & 5.36 & 17.43 & 0.01 \\
\hline & Mild:Strong & 1 & 0.04 & 0.12 & 0.84 \\
\hline & Residuals & 8 & 2.46 & & \\
\hline \multirow{3}{*}{ RLCS06 } & Mild & 1 & 2.02 & 7.87 & 0.05 \\
\hline & Strong & 1 & 4.91 & 19.11 & 0.01 \\
\hline & Mild:Strong & 1 & 8.50 & 33.07 & 0.01 \\
\hline
\end{tabular}


bioRxiv preprint doi: https://doi.org/10.1101/733923; this version posted August 14,2019 . The copyright holder for this preprint (which was not certified by peer review) is the author/funder, who has granted bioRxiv a license to display the preprint in perpetuity. It is made available under aCC-BY-NC-ND 4.0 International license.

\begin{tabular}{|c|c|c|c|c|c|}
\hline & Residuals & 8 & 2.06 & & \\
\hline \multirow{4}{*}{ RLCS27 } & Mild & 1 & 0.06 & 0.99 & 0.51 \\
\hline & Strong & 1 & 0.05 & 0.77 & 0.45 \\
\hline & Mild:Strong & 1 & 3.43 & 55.08 & 0.00 \\
\hline & Residuals & 8 & 0.50 & & \\
\hline \multirow{4}{*}{ RLCS13 } & Mild & 1 & 0.00 & 0.01 & 0.96 \\
\hline & Strong & 1 & 0.55 & 11.29 & 0.02 \\
\hline & Mild:Strong & 1 & 1.20 & 24.41 & 0.00 \\
\hline & Residuals & 8 & 0.39 & & \\
\hline \multirow{4}{*}{ RLCS32 } & Mild & 1 & 4.35 & 26.68 & 0.00 \\
\hline & Strong & 1 & 7.73 & 47.34 & 0.00 \\
\hline & Mild:Strong & 1 & 23.84 & 146.09 & 0.00 \\
\hline & Residuals & 8 & 1.31 & & \\
\hline \multirow{4}{*}{ RLCS18 } & Mild & 1 & 2.02 & 4.92 & 0.11 \\
\hline & Strong & 1 & 0.00 & 0.00 & 1.00 \\
\hline & Mild:Strong & 1 & 1.02 & 2.49 & 0.20 \\
\hline & Residuals & 8 & 3.29 & & \\
\hline \multirow{4}{*}{ RLCS05 } & Mild & 1 & 1.26 & 25.75 & 0.00 \\
\hline & Strong & 1 & 0.30 & 6.06 & 0.05 \\
\hline & Mild:Strong & 1 & 15.64 & 320.18 & 0.00 \\
\hline & Residuals & 8 & 0.39 & & \\
\hline \multirow{4}{*}{ RLCS08 } & Mild & 1 & 3.75 & 33.25 & 0.00 \\
\hline & Strong & 1 & 1.68 & 14.92 & 0.01 \\
\hline & Mild:Strong & 1 & 2.78 & 24.68 & 0.00 \\
\hline & Residuals & 8 & 0.90 & & \\
\hline \multirow{4}{*}{ RLCS24 } & Mild & 1 & 0.10 & 5.25 & 0.11 \\
\hline & Strong & 1 & 0.20 & 10.26 & 0.02 \\
\hline & Mild:Strong & 1 & 0.20 & 10.59 & 0.02 \\
\hline & Residuals & 8 & 0.15 & & \\
\hline \multirow{4}{*}{ RLCS23 } & Mild & 1 & 0.65 & 0.84 & 0.52 \\
\hline & Strong & 1 & 3.97 & 5.13 & 0.07 \\
\hline & Mild:Strong & 1 & 0.04 & 0.06 & 0.85 \\
\hline & Residuals & 8 & 6.18 & & \\
\hline \multirow{4}{*}{ RLCS20 } & Mild & 1 & 0.09 & 1.84 & 0.38 \\
\hline & Strong & 1 & 0.05 & 1.02 & 0.39 \\
\hline & Mild:Strong & 1 & 0.29 & 6.31 & 0.06 \\
\hline & Residuals & 8 & 0.37 & & \\
\hline \multirow{4}{*}{ RLCS25 } & Mild & 1 & 0.41 & 0.89 & 0.52 \\
\hline & Strong & 1 & 1.13 & 2.43 & 0.19 \\
\hline & Mild:Strong & 1 & 0.69 & 1.49 & 0.32 \\
\hline & Residuals & 8 & 3.70 & & \\
\hline \multirow{4}{*}{ RLCS11 } & Mild & 1 & 6.85 & 55.56 & 0.00 \\
\hline & Strong & 1 & 8.29 & 67.20 & 0.00 \\
\hline & Mild:Strong & 1 & 3.75 & 30.43 & 0.00 \\
\hline & Residuals & 8 & 0.99 & & \\
\hline \multirow{4}{*}{ RLCS03 } & Mild & 1 & 18.31 & 15.27 & 0.01 \\
\hline & Strong & 1 & 34.08 & 28.43 & 0.00 \\
\hline & Mild:Strong & 1 & 20.34 & 16.96 & 0.01 \\
\hline & Residuals & 8 & 9.59 & & \\
\hline \multirow{2}{*}{ RLCS04 } & Mild & 1 & 76.09 & 30.59 & 0.00 \\
\hline & Strong & 1 & 76.09 & 30.59 & 0.00 \\
\hline
\end{tabular}




\begin{tabular}{|c|c|c|c|c|c|}
\hline & Mild:Strong & 1 & 7.16 & 2.88 & 0.18 \\
\hline & Residuals & 8 & 19.90 & & \\
\hline \multirow{4}{*}{ RLCSO2 } & Mild & 1 & 40.87 & 40.32 & 0.00 \\
\hline & Strong & 1 & 56.10 & 55.34 & 0.00 \\
\hline & Mild:Strong & 1 & 23.09 & 22.78 & 0.00 \\
\hline & Residuals & 8 & 8.11 & & \\
\hline \multirow{4}{*}{ RLCS15 } & Mild & 1 & 11.36 & 13.86 & 0.02 \\
\hline & Strong & 1 & 23.69 & 28.90 & 0.00 \\
\hline & Mild:Strong & 1 & 5.09 & 6.21 & 0.06 \\
\hline & Residuals & 8 & 6.56 & & \\
\hline \multirow{4}{*}{ RLCS01 } & Mild & 1 & 0.52 & 0.53 & 0.60 \\
\hline & Strong & 1 & 0.07 & 0.07 & 0.85 \\
\hline & Mild:Strong & 1 & 4.56 & 4.62 & 0.10 \\
\hline & Residuals & 8 & 7.90 & & \\
\hline \multirow{4}{*}{ RLCS19 } & Mild & 1 & 0.00 & 0.02 & 0.96 \\
\hline & Strong & 1 & 2.30 & 9.93 & 0.02 \\
\hline & Mild:Strong & 1 & 0.01 & 0.03 & 0.87 \\
\hline & Residuals & 8 & 1.62 & & \\
\hline
\end{tabular}

Fig. 2
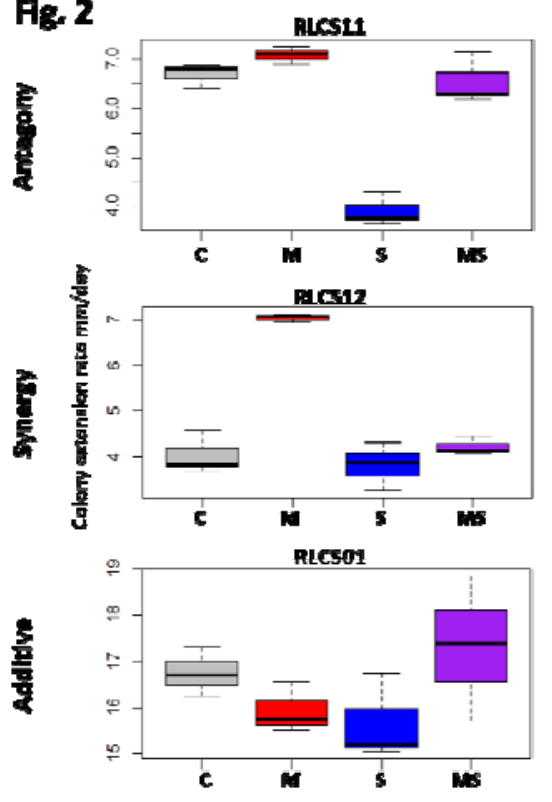
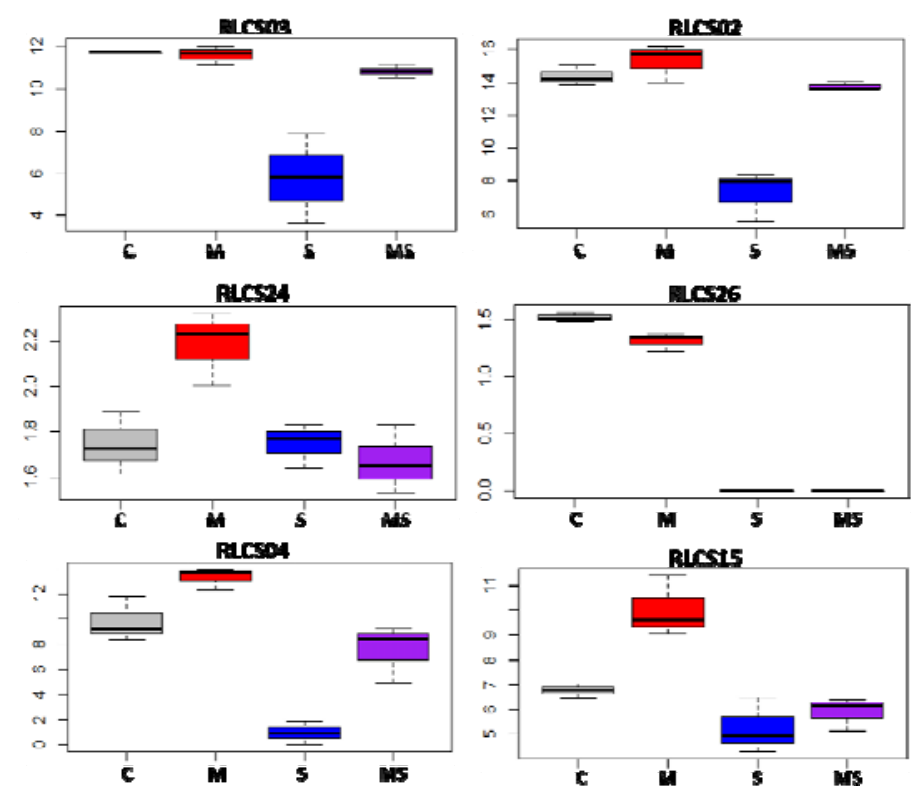

Figure 2. Examples of response categories (based on colony extension rate) to applied recurrent heat pulse perturbations: antagony (shown are 3 of the 13 isolates so categorized), synergy (all 3 isolates in this category are shown), additive ( 3 of the 16 isolates so categorized are depicted). For a full figure containing data for all 32 isolates see Supplementary materials (Figure S1, Supplementary materials). 
Fig. 3
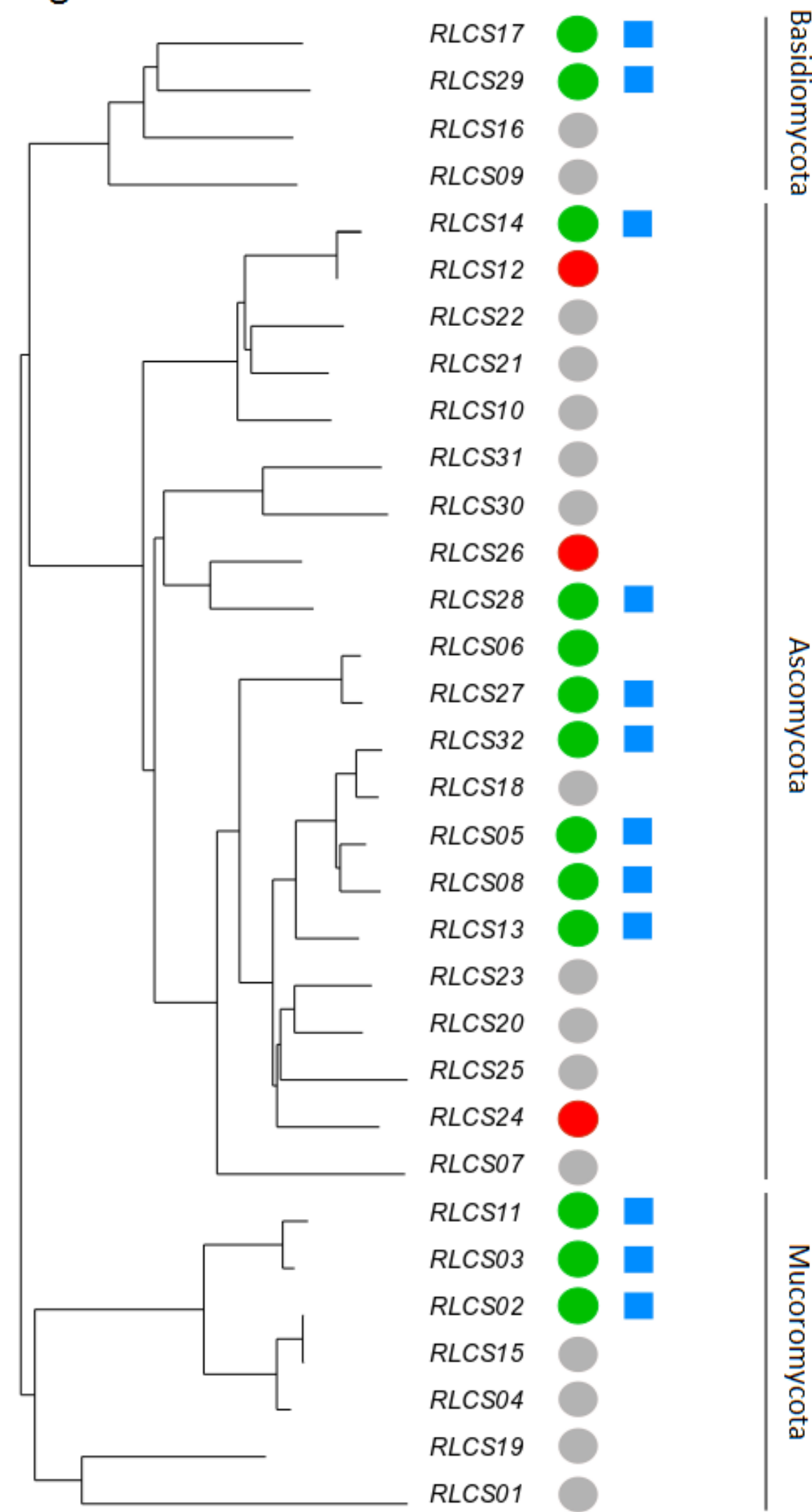

RLCS14

RLCS12

RLCS 22

RLCS21

RLCS10

RLCS31

RLCS 30

RLCS26

RLCS28

RLCSO6

RLCS27

RLCS32

RLCS18

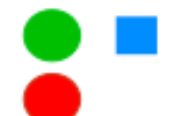

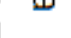

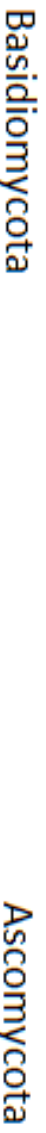

RLCSO5

RLCS08

RLCS13

RLCS 23

RLCS 20

RLCS25

RLCS24

RLCSO7

RLCS11

RLCSO3

RLCSO2

RLCS15

RLCS04

RLCS19

RLCS01 
Figure 3. Phylogenetic relationship of a set of soil fungal isolates originating from the same field site with the representation of diverse responses of fungal colony extension rate to recurrent heat pulse perturbations $\left(2 \mathrm{~h}\right.$ mild perturbation $35^{\circ} \mathrm{C}+1 \mathrm{~h}$ strong perturbation $45^{\circ} \mathrm{C}$ ). The colored circles represent response types: antagony (green) (13 isolates); synergy (red) (3 isolates); additive (grey) (16 isolates). Blue squares mark isolates (12) that showed priming ability (based on criteria of Andrade-Linares et al. (2016)). The remaining isolates (19) did not meet the criteria of priming ability. The neighbor-joining tree was based on ITS and LSU regions; detailed information on isolates is in Supplementary materials (Supplementary materials, Table S1).

\section{Discussion}

Here we show for the first time that exposure of soil saprobic fungi isolates to the same sequence of pulse temperature perturbations results in a range of response types that include additive effect, antagony and synergy. The applied temperature pulse regime was exceeding the temperatures that are currently typically observed at the site from which isolates were obtained. The biggest proportion of isolates (16/32) responded in an additive manner to the perturbations. The synergistic response (two perturbations leading to decreased performance) was observed for $3 / 32$ isolates, meaning that such a sequence of perturbations could limit rates of processes (e.g. decomposition) these species carry out. On the other hand, the same temperature pulse regime resulted in an antagonistic response (two perturbations leading to an increased performance of an organism) for over $40 \%$ of isolates.

The observed antagonistic response of 12 isolates is congruent with priming ability of isolates. Priming ability of 8 filamentous fungi isolates exposed to a radically different temperature sequence $\left(5 \mathrm{~h} / 35^{\circ} \mathrm{C}\right.$, then $40^{\circ} \mathrm{C} / 10 \mathrm{~h}$ ) has been shown previously (AndradeLinares et al. 2016). The fact that a large proportion of our fungi showed this improved 
response to sequential stresses, even under different temperature regimes, may indicate that this priming ability is not an exceptional response, but rather a well-established phenomenon that can help fungi deal with adverse effects.

In addition, the observed exacerbation of growth inhibition of three treated isolates (RLCS06, RLCS12, RLCS24) due to sequential heat exposure has not been observed before. For these fungi, the first heat stress event clearly did not help them in dealing with the second, more severe heat pulse. These would therefore be interesting targets to study further in the context of climate change and heat extremes.

At the species level, physiological stress regimes are known to set biogeographic limits and determine microhabitat preferences. Organismal responses to extreme heat events include redirecting resources from growth to survival that may include transition to a dormancy state or sporulation. These variations in heat responses are species specific and may be caused by differences in cellular HSP (heat shock proteins) production, altered membrane composition and carbohydrate flux (Morano et al. 2012; Bernard et al. 2015). The difference in response to sequential temperature pulse perturbation in isolates originating from one fungal assembly may indicate differences in sensitivity and diverse stress tolerances.

Our results show that recurrent environmental perturbations such as extreme temperature events influence a group of soil filamentous fungi originating from the same site in various ways. Thus, the patterns of responses that they exhibit to the sequence of thermal pulses might be one of the factors that contribute to shaping soil fungal community composition. Such differences in the 'thermal niche' may contribute to coexistence of fungi in the community, much likely differences among species in other abiotic factors or resource utilization patterns. 


\section{Conclusion}

We focused on physiological responses of multiple isolates of soil filamentous fungi, originating from the same grassland to a sequence of thermal pulses. These fungal isolates revealed the full range of possible responses. This could have consequences for soil-borne ecosystem services, highlighting the potential importance of fungal biodiversity in maintaining such services, particularly in the context of climate change.

\section{Acknowledgement}

We acknowledge funding for CRC 973 Project A1 'Priming and memory of stress organismic responses to stress' from the German Research Foundation (DFG).

\section{References}

Alley R. B., Marotzke J., Nordhaus W. D., Overpeck J. T., Peteet D. M., Pielke R. A. Jr, Pierrehumbert R. T., Rhines P. B., Stocker T. F., Talley L. D., Wallace J. M. Abrupt Climate Change, (2003) Science 299 (5615), 2005-2010, https://doi.org/10.1126/science.1081056

Allison, S. D., \& Martiny, J. B. H. Resistance, resilience, and redundancy in microbial communities. Proceedings of the National Academy of Sciences, (2008), 105(Supplement 1), 11512-11519. https://doi.org/10.1073/pnas.0801925105

Andrade-Linares, D. R., Veresoglou, S. D., \& Rillig, M. C. Temperature priming and memory in soil filamentous fungi. Fungal Ecology, (2016) 21, 10-15. https://doi.org/10.1016/j.funeco.2016.02.002 
Bahn, M., Reichstein, M., Dukes, J. S., Smith, M. D., \& Mcdowell, N. G. Climatebiosphere interactions in a more extreme world. New Phytologist, (2014), 202(2), 356-359. https://doi.org/10.1111/nph.12662

Bárcenas-Moreno, G., Brandón, M. G., Rousk, J., \& Bååth, E. Adaptation of soil microbial communities to temperature: Comparison of fungi and bacteria in a laboratory experiment. Global Change Biology, (2009), 15(12), 2950-2957. https://doi.org/10.1111/j.1365-2486.2009.01882.x

Bérard, A., Sassi, M. Ben, Kaisermann, A., \& Renault, P.. Soil microbial community responses to heat wave components: Drought and high temperature. Climate Research, (2015), 66(3), 243-264. https://doi.org/10.3354/cr01343

Côté I.M., Darling, E. S., \& Brown, C. J. Interactions among ecosystem stressors and their importance in conservation. Proceedings of the Royal Society B: Biological Sciences, (2016), 283(1824), 1-9. https://doi.org/10.1098/rspb.2015.2592

Crain C.A., Kroeker K., Halpern B.S. Interactive and cumulative effects of multiple human stressors in marine systems. Ecology Letters, (2008) 11: 1304-1315 doi: $10.1111 / \mathrm{j} .1461-0248.2008 .01253$

Crowther T. W., \& Bradford M. A. Thermal acclimation in widespread heterotrophic soil microbes. Ecology Letters, (2013), 16(4), 469-477. https://doi.org/10.1111/ele.12069

Fischer E.M., Knutti R. Anthropogenic contribution to global occurrence of heavyprecipitation and high-temperature extremes. Nature Climate Change volume 5, pages 560-564 (2015), https://doi.org/10.1038/nclimate2617

Foster C.N., Sato C.F., Lindenmayer D.B., Barton P.S. Integrating theory into disturbance interaction experiments to better inform ecosystem management Global Change Biology (2016) 22, 1325-1335, https://doi.org/10.1111/gcb.13155

Frank D., Reichstein M., Bahn M., Thonicke K., Frank D., Mahecha M. D., ... Zscheischler J. Effects of climate extremes on the terrestrial carbon cycle: Concepts, processes 
and potential future impacts. Global Change Biology, (2015) 21(8), 2861-2880. https://doi.org/10.1111/gcb.12916

Hanson C.E., Palutikof J.P., Dlugolecki A., \& Giannakopoulos C. Bridging the gap between science and the stakeholder: The case of climate change research. Climate Research, (2006), 31(1), 121-133. https://doi.org/10.3354/cr031121

Hortal S., Powell J. R., Plett J. M., Simonin A., Anderson I. C. Intraspecific competition between ectomycorrhizal Pisolithus microcarpus isolates impacts plant and fungal performance under elevated $\mathrm{CO} 2$ and temperature. FEMS Microbiology Ecology, Volume 92, Issue 8, (2016), fiw113, https://doi.org/10.1093/femsec/fiw113

Hilker M., Schwachtje J., Baier M., Balazadeh S., Isabel B., Geiselhardt S., ... Kopka J. Priming and memory of stress responses in organisms lacking a nervous system, (2016), 49, 1118-1133. https://doi.org/10.1111/brv.12215

IPCC 2018: Global warming of $1.5^{\circ} \mathrm{C}$. An IPCC Special Report on the impacts of global warming of $1.5^{\circ} \mathrm{C}$ above pre-industrial levels and related global greenhouse gas emission pathways, in the context of strengthening the global response to the threat of climate change, sustainable development, and efforts to eradicate poverty [V. Masson-Delmotte, P. Zhai, H. O. Pörtner, D. Roberts, J. Skea, P.R. Shukla, A. Pirani, W. Moufouma-Okia, C. Péan, R. Pidcock, S. Connors, J. B. R. Matthews, Y. Chen, X. Zhou, M. I. Gomis, E. Lonnoy, T. Maycock, M. Tignor, T. Waterfield (eds.)]. In Press.

Jentsch A., Kreyling J., \& Beierkuhnlein C. . A new generation of events, not trends experiments?]: Frontiers in Ecology and the Environment, (2007), 5(7), 365-374. https://doi.org/10.1890/1540-9295(2007)5[365:ANGOCE]2.0.CO;2

Kayler, Z. E., De Boeck, H. J., Fatichi, S., Grünzweig, J. M., Merbold, L., Beier, C., ... Dukes, J. S. (2015). Experiments to confront the environmental extremes of climate change. Frontiers in Ecology and the Environment, 13(4), 219-225. https://doi.org/10.1890/140174 
Kreyling, J., \& Beier, C. Complexity in Climate Change Manipulation Experiments. BioScience, (2013), 63(9), 763-767. https://doi.org/10.1525/bio.2013.63.9.12

Lloret F., Escudero A., Iriondo J.M., Martinez-Vilalta J., Valladarez F. Extreme climatic events and vegetation: The role of stabilizing processes. Global Change Biology, (2012), 18(3):797 - 805, doi: 10.1111/j.1365-2486.2011.02624.x

Mittler, R. Abiotic stress, the field environment and stress combination. Trends in Plant Science, (2006), 11(1), 15-19. https://doi.org/10.1016/j.tplants.2005.11.002

Morano K.A., Grant C.M., \& Moye-Rowley W.S. The response to heat shock and oxidative stress in saccharomyces cerevisiae. Genetics, (2012), 190(4), 1157-1195. https://doi.org/10.1534/genetics.111.128033

Norris T.B., Wraith J.M., Castenholz R.W., McDermott T.R. Soil Microbial Community Structure across a Thermal Gradient following a Geothermal Heating Event. Applied And Environmental Microbiology, (2002), p. 6300-6309 Vol. 68, No. 12, https://doi.org/10.1128/AEM.68.12.6300-6309.2002

Piggott J.J., Townsend C.R., Matthaei C.D. Reconceptualizing synergism and antagonism among multiple stressors. Ecol Evol. (2015) ;5(7):1538-47. https://doi.org/10.1002/ece3.1465

Rillig M.C., Rolff J., Tietjen B., Wehner J., Andrade-Linares D.R. Community primingeffects of sequential stressors on microbial assemblages. FEMS Microbiology Ecology, Volume 91, Issue 5, (2015), fiv040, https://doi.org/10.1093/femsec/fiv040

Ryo, M., Aguilar-trigueros C. A., Pinek L., Muller L. A. H. \& Rillig M. C. Basic Principles of Temporal Dynamics. Trends in Ecology \& Evolution, (2019), xx, 1-11. https://doi.org/10.1016/j.tree.2019.03.007

Thompson R.M., Beardall J., Beringer J., Grace M., \& Sardina P. Means and extremes: Building variability into community-level climate change experiments. Ecology Letters, (2013), 16(6), 799-806. https://doi.org/10.1111/ele.12095 
bioRxiv preprint doi: https://doi.org/10.1101/733923; this version posted August 14,2019 . The copyright holder for this preprint (which was not certified by peer review) is the author/funder, who has granted bioRxiv a license to display the preprint in perpetuity. It is made available under aCC-BY-NC-ND 4.0 International license.

Vázquez D.P., Gianoli E., Morris W.F., Bozinovic F. Ecological and evolutionary impacts of changing climatic variability. Biol. Rev. (2015), pp. 000-000. 1, doi: $10.1111 /$ brv.12216

Zhou W.P., Shen W.J., Li Y.E., Hui D.F. (2017). Interactive effects of temperature and moisture on composition of the soil microbial community. European Journal of Soil Science, 68(6), 909-918. https://doi.org/10.1111/ejss.12488 